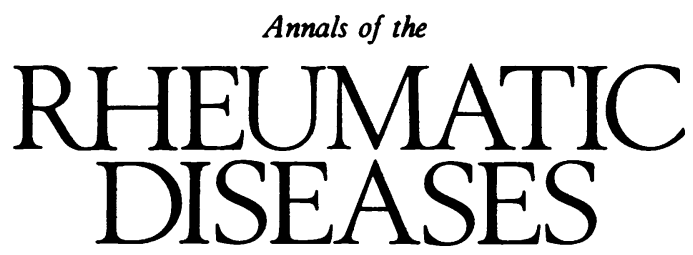

Leader

\title{
The gold plated stomach?
}

The prevalence of gastric disorders in arthritic patients makes one wish that the stomach was better protected or 'gold plated'. This description might not be wishful thinking given the recent finding that non-steroidal antiinflammatory drug (NSAID) related peptic ulcers are less common in gold treated patients than in those receiving other second line drugs. ${ }^{1}$ Indeed, as some rheumatologists are rethinking the value of gold treatment in rheumatoid arthritis (RA), ${ }^{2-5}$ an increased interest in this precious metal has been shown by gastroenterologists ${ }^{1}$ 6-10 because of its potential benefits in peptic ulcer disease.

The varying degree of interest in gold treatment, noted over the years, has each time been linked to its antibacterial activity. A century after gold was used in the treatment of tuberculosis $^{11}$ and 60 years after its first use in the treatment of $\mathrm{RA},{ }^{12}$ then thought to be tuberculous in origin, the drug is now being reconsidered in the treatment of another infection: Helicobacter pylori, ${ }^{6-10}$ which has been linked to peptic ulcer disease.

Not unlike its antirheumatoid activity, the effect of gold on the gastric mucosa is still poorly understood. Its apparently protective effects on the stomach are in contrast with those on the colonic mucosa where it may cause colitis. ${ }^{13}$ Gold may affect factors involved in the pathogenesis of peptic ulcer disease, including gastric acid, $H$ pylori, and NSAIDs, and the protective factors, including mucosal prostaglandins, bicarbonate secretion, and the mucus layer. These factors cannot always be considered separately, as the individual patient might be infected with $H$ pylori, receiving an NSAID with decreased gastric prostaglandin synthesis, all of which increase the risk of ulcer formation.

The effect of gold on gastric acid secretion has not been studied. Despite its importance the role of acid in the pathogenesis of peptic ulcers in rheumatoid patients might not be critical, as many patients with RA tend to have hypochlorhydria. ${ }^{14}$ Also, the effect of gold on gastric prostaglandins, mucus, and bicarbonate secretion remains speculative. As gold and bismuth are classified close to one another in the periodic table of elements it might be justifiable to suppose that their mode of action might be similar. ${ }^{16}$ Colloidal bismuth subcitrate was found to have a protective effect against aspirin induced gastric microbleeding, and this protection occurred despite suppression of mucosal prostaglandin production by aspirin. ${ }^{15}$ In addition, colloidal bismuth subcitrate was shown to stimulate gastric and duodenal alkaline secretion through a prostaglandin dependent mechanism. ${ }^{16}$ Whether gold possesses similar favourable properties to bismuth needs to be investigated.
More is known about the interaction between gold, $H$ pylori and NSAIDs than that between gold and other factors, such as acid, prostaglandins, and bicarbonate secretion. The low prevalence of $H$ pylori in rheumatoid patients treated with gold compounds might be due to either a direct bactericidal effect, as shown by in vitro studies, " or inhibition of $H$ pylori urease activity, ${ }^{7}$ or both. The failure of some studies to show any significant effect of gold on $H$ pylori colonisation ${ }^{8}$ might be explained by the difference in the methodology of detecting $H$ pylori organisms: unlike culture, histology, and the CLO test, which involve gastric biopsies, the specificity of some serological tests for $H$ pylori might be less reliable in $\mathrm{RA} .{ }^{17}$ The immunomodulatory activity of gold is another mechanism by which this agent might influence the survival of $H$ pylori, and this is of particular relevance to patients with RA. It has been noted that immunodeficient patients are less likely to be infected with $H$ pylori, possibly owing to impaired host cellular immune responses. ${ }^{18} 19$ Sulphasalazine, known to have antiarthritic activity comparable with that of gold does not seem to affect the prevalence of $H$ pylori. ${ }^{10}$

Chronic suppression, rather than eradication of $H$ pylori by gold compounds, might also explain the smaller number of cases of detectable organisms in biopsy specimens taken from long term gold users. ${ }^{10}$ This implies that $H$ pylori might recur or become more easily detectable upon the withdrawal of gold treatment. The presumed effect of intramuscular gold on $H$ pylor ${ }^{10}$ is thought to be due to the distribution of gold into the gastric mucosa, gastric secretions, or both. There have been no studies on gastric tissue or gastric juice concentrations of gold, but it can be speculated that such concentrations might be higher if oral gold preparations were used, which in turn might be more effective against $H$ pylori.

Gold continues to be an intriguing precious metal which has fascinating and complicated activities in biological systems. An understanding of its effects on $H$ pylori may yield useful information germane to its mode of action in RA. Its gastroprotective properties are a surprising and a welcome bonus to patients with RA whose stomachs are otherwise exposed to the insults of their antirheumatic treatment.

University Department of

Medicine, Glasgow Roval

Infirmarv, Glasgow (j3I $2 E R$

Correspondence to: Professor Sturrock. 
1 Taha A S, Capell H A, Sturrock R D, Russell R I. Non-steroidal peptic damage in rheumatoid patients receiving second-line drugs. Am $\mathcal{F}$ Gastroenterol 1991; 86: 1588-91.

2 Epstein W V. Parenteral gold therapy for rheumatoid arthritis: a treatmen whose time has gone. $\mathcal{f}$ Rheumatol 1989; 16: 1291-4.

3 Epstein W V, Henke C J, Yelin E H, Kat\% P P. Effects of parenterally administered gold therapy on the course of adult rheumatoid arthritis. Ann Intern Med 1991; 114: 437-44.

4 Corkill M M, Kirkham B W, Chicanza I C, Gibson T, Panayi G S Intramuscular depot methyl prednisolone induction of chrysotherapy in rheumatoid arthritis: a 24 week randomized controlled trial. Br $\mathcal{Z}$ Rheumatol 1990; 29: 274-9.

5 Lehtinen $\mathrm{K}$, Isomaki $\mathrm{H}$. Intramuscular gold therapy is associated with long survival in patients with rheumatoid arthritis. 7 Rheumatol 1991; 18.524-9.

6 Barga L L, Sarosiek J, Marshall B, McCallum R W, Barret L, Guerrant R. Gold-a new potential drug for the treatment of Helicobacter pylori

7 Sarosiek J, Roche J K, McCallum R W, Marshall B. Urease-gold sodium thiomalate complex in inhibition of urease activity. Gastroenterologv 1990 98: A119.

8 Gubbins G P, Schubert T T, Attanasio F, Lubetsky M, Perez-Perez G I Blaser $M$ J. Gold and seroprevalence of Helicobacter pylori in rheumatoid patients. Gastroenterology 1991; 100: A76.

$9 \mathrm{Yu} \mathrm{Z} \mathrm{J}$, Sarosiek J, Feng T, et al. Colonisation of gastroduodenal mucosa with Helicobacter pylori in patients with rheumatoid arthritis during treatment with gold compounds. Gastroenterology 1991; 100: A190.
10 Taha A S, Sturrock R D, Russell R I. Helicobacter pylori and peptic ulcers in rheumatoid arthritis patients receiving gold, sulphasalazine and nonsteroidal anti-inflammatory drugs. $A m \mathcal{F}$ Gastroenterol. In press.

11 Koch R. Weitere Mittheilungen uber ein Heilmittel gegen Tuberculose. Dtsch Med Wochenschr 1890; 16: 1029-32.

12 Forestier J. L'aurotherapies dans les rheumations chroniques. Bulletins e Memoires de la Societe Medicale des Hopitaux de Paris 1929; 44: 323.

13 Wright A, Benfield G F A, Felix-Davis D. Ischaemic colitis and immune complexes during gold therapy for rheumatoid arthritis. Ann Rheum Dis 1984; 43: 495-7.

14 De Witte T J, Geerdink P J, Lamers G B, Boerbooms A M van der Krost $\mathrm{J}$ K. Hypochlorhydria and hypergastrinaemia in rheumatoid arthritis. Ann Rheum Dis 1979; 38: 14-17.

15 Konturek S J, Kweicien N, Obtulowicz W, et al. Effects of colloidal bismuth subcitrate on aspirin induced gastric microbleeding, DNA loss, and prostaglandin formation in humans. Scand $\mathcal{F}$ Gastroenterol 1988; 23: 861-6.

16 Konturek S J, Bilski J, Kwiecien N, et al. De-Nol stimulates gastric and duodenal alkaline secretion through prostaglandin dependent mechanism Gut 1987; 28: 1557-63.

17 Taha A S, Boothman P, Nakshabendi I, et al. Diagnostic tests for Helicobacter pylori-comparison and influence of non-steroidal antiinflammatory drugs. F Clin Pathol 1992; 45: 709-12.

18 Rathbone B J, Wyatt J I, Heatley V. Immunological aspects of Campylobacter pylori infection. Eur f Gastroenterol 1989; 1: 13-16.

19 Logan R H P, Polson R J, Rao G, et al. Helicobacter pylori and HIV infection. Lancet 1990; 335: 1456 . 